\title{
Mortality and Revision Surgery Are Increased in Patients With Parkinson's Disease and Fractures of the Femoral Neck
}

\author{
Mark S. Karadsheh MD, Michael Weaver MD, Kenneth Rodriguez MD, PhD, \\ Mitchel Harris MD, David Zurakowski PhD, Robert Lucas BA
}

Received: 29 November 2014/Accepted: 13 March 2015/Published online: 24 March 2015

(C) The Association of Bone and Joint Surgeons (B) 2015

\begin{abstract}
Background Patients with Parkinson's disease are at increased risk for falls and associated hip fractures as a result of tremor, bradykinesia, rigidity, and postural instability. The available literature is limited and conflicting regarding the optimal surgical treatment and risk for postoperative complications and mortality in this unique patient population.

Questions/purposes We asked: (1) Is there a difference in mortality after surgical treatment of hip fractures in patients with Parkinson's disease compared with similar

Each author certifies that he or she, or a member of his or her immediate family, has no funding or commercial associations (eg, consultancies, stock ownership, equity interest, patent/licensing arrangements, etc) that might pose a conflict of interest in connection with the submitted article.

All ICMJE Conflict of Interest Forms for authors and Clinical Orthopaedics and Related Research ${ }^{\circledR}$ editors and board members are on file with the publication and can be viewed on request.

Clinical Orthopaedics and Related Research ${ }^{\mathbb{R}}$ neither advocates nor endorses the use of any treatment, drug, or device. Readers are encouraged to always seek additional information, including FDAapproval status, of any drug or device prior to clinical use.

Each author certifies that his or her institution approved the human protocol for this investigation, that all investigations were conducted in conformity with ethical principles of research, and that informed consent for participation in the study was obtained.

This work was performed at Brigham and Women's Hospital, Harvard Medical School, MA, USA.
\end{abstract}

M. S. Karadsheh, M. Weaver, K. Rodriguez, M. Harris Partners Healthcare, Boston, MA, USA

M. S. Karadsheh, M. Weaver, K. Rodriguez, M. Harris

Harvard Orthopaedics, Boston, MA, USA

D. Zurakowski

Harvard Medical School, Boston, MA, USA patients with hip fractures without Parkinson's disease? (2) Does Parkinson's disease lead to a higher rate of reoperation after operative treatment of femoral neck fractures? (3) Does Parkinson's disease lead to a higher rate of dislocation after hemiarthroplasty for displaced femoral neck fractures, and (4) does the operative approach affect dislocation rates?

Methods In this case-controlled study, we retrospectively reviewed 141 patients with a diagnosis of Parkinson's disease and a fracture of the femoral neck. Each patient with Parkinson's disease was matched with two control patients ( $n=282)$ without Parkinson's disease stratified by age, sex, American Society of Anesthesiologists classification, and fracture type (nondisplaced/displaced). Clinical outcomes included mortality after surgical intervention, rate of reoperation, dislocation events after hemiarthroplasty, and the rate of failure after internal fixation for nondisplaced fractures.

Results The median survival time of the patients with Parkinson's disease after fracture was 31 months (95\% CI, 25-37 months) compared with 45 months (95\% CI, $39-50$ months) in our control group $(\mathrm{p}=0.007)$. The rate of reoperation for displaced and nondisplaced fractures was higher in the Parkinson's disease group compared with the control group $(11 \%$ versus $4 \%$; $\mathrm{p}=0.005)$. Failure of fixation for patients treated with internal fixation of nondisplaced femoral neck fractures was significantly

\author{
R. Lucas \\ Harvard Orthopaedic Trauma Research Division, Boston, MA, \\ USA \\ M. S. Karadsheh ( $\square)$ \\ Department of Orthopaedic Surgery, Brigham and Women's \\ Hospital, 75 Francis Street, Boston, MA 02115, USA \\ e-mail: mkaradsh@umich.edu
}


higher in the Parkinson's disease group compared with our control group (22\% versus $5 \% ; \mathrm{p}=0.01)$. Dislocation rates after hemiarthroplasty were significantly higher in the Parkinson's disease group compared with the control group ( $8 \%$ versus $1 \% ; p=0.003)$. Patients treated with a hemiarthroplasty through an anterolateral approach had a significantly lower dislocation rate compared with those treated with a posterior approach (2\% versus $15 \%$; $\mathrm{p}=0.002$ ).

Conclusions Parkinson's disease is an independent predictor of mortality after femoral neck fracture and is associated with an increased rate of dislocation, revision surgery, and failure of internal fixation. Although patients with Parkinson's disease with a nondisplaced or valgus impacted femoral neck fracture may be treated with internal fixation, they are at significantly higher risk of failure of fixation compared with patients without Parkinson's disease. Use of a hemiarthroplasty through an anterolateral approach may reduce the likelihood of requiring a revision operation.

Level of Evidence Level III, therapeutic study.

\section{Introduction}

Parkinson's disease is a neurodegenerative disorder of unknown cause that results in tremor, rigidity, and akinesia [12]. Its prevalence varies depending on diagnostic criteria but is estimated to be $1 \%$ in people older than 60 years [17]. Falls are common [39] with literature documenting up to a ninefold increased risk [4]. In addition, patients with Parkinson's disease are at an increased risk for osteoporosis [28]. Therefore, it is not surprising that these patients have a four times greater prevalence of hip fractures compared with a control population [2].

Although the mortality rate after a hip fracture has been well documented among the general population, less is known regarding the mortality rate after hip fracture in patients with Parkinson's disease. Previous studies have shown a large variation in the 6-month mortality rate $(14 \%-47 \%)$ in patients with Parkinson's disease [6, 32, 35]. Although the primary factors associated with the increased mortality rate of patients with Parkinson's disease and hip fractures is unknown, it is believed that associated comorbidities and difficulties with rehabilitation are responsible.

Current literature is scarce and conflicting regarding optimal surgical management, revision rate, and complications after internal fixation or prosthetic replacement of hip fractures in patients with Parkinson's disease. Some authors have noted excessively high dislocation rates in patients treated with hemiarthroplasty, leading to the conclusion that even displaced fractures should be treated with internal fixation [6, 35]. The question remains whether Parkinson's disease is a unique risk factor when treating femoral neck fractures, particularly in light of advances in pharmacologic $[26,29]$ and surgical treatment during the last two decades.

We asked: (1) Is there a difference in mortality after surgical treatment of hip fractures in patients with Parkinson's disease compared with similar patients with hip fractures without Parkinson's disease? (2) Does Parkinson's disease lead to a higher rate of reoperation after operative treatment of femoral neck fractures? (3) Does Parkinson's disease lead to a higher rate of dislocation after hemiarthroplasty for displaced femoral neck fractures, and (4) does the operative approach affect dislocation rates?

\section{Patients and Methods}

We performed a case-controlled, retrospective study at two tertiary care American College of Surgeons-verified Level I trauma centers. Patients were identified and data were collected from a 20-year period from March 1994 to April 2014. Before initiating the study, institutional review board approval was obtained.

Patients with a diagnosis of Parkinson's disease and a proximal femur fracture were obtained through review of the hospital billing database and medical records $(\mathrm{n}=260)$. Patients with Parkinson's disease as determined by hospital billing were confirmed through our medical records, ensuring the diagnosis was present before fracture. Patients were excluded if they met any of the following criteria: age younger than 60 years, diagnosis of Parkinson's disease initially made after treatment of the hip fracture, a fracture pattern distal to the femoral neck (basicervical) region, pathologic fracture, a history of previous hip surgery, or insufficient patient data for analysis.

A control group of patients at the same hospitals who had fractures of the femoral neck without a diagnosis of Parkinson's disease then were gathered using similar exclusion criteria. These patients were randomly matched two to one with patients from the Parkinson's disease group based on age \pm 5 years, sex, American Society of Anesthesiologists (ASA) classification, and operation performed. Charts were reviewed and similar data were collected for comparison. This yielded the final patient cohort of 141 patients with Parkinson's disease and 282 patients without Parkinson's disease.

Radiographs were reviewed and fractures were categorized as displaced or nondisplaced. In our Parkinson's group, all patients with nondisplaced fractures were treated with internal fixation, whereas all displaced fractures were treated with hemiarthroplasty through a posterior or 
anterolateral approach to the hip. Internal fixation included closed reduction with cannulated screw fixation and closed reduction with dynamic hip screw fixation. Surgeries were performed by a total of 42 different surgeons at the two institutions where data were collected.

The medical records then were comprehensively reviewed and the following data were abstracted: age at injury, sex, attending surgeon, date of injury, ASA physical status classification based on anesthesia records, fracture displacement (displaced or nondisplaced), operation performed, approach used, cement or cementless technique for patients undergoing hemiarthroplasty, length of hospitalization before discharge, postdischarge data including length of followup, length of stay, evidence of infection (as defined by positive cultures on aspiration or during débridement), revision procedures, and dislocation events. Mortality data were obtained through the medical record and the Social Security Death Index.

Our primary outcome measure was mortality. Secondary outcomes included reoperation, dislocation among patients undergoing hemiarthroplasty, fixation failure among patients undergoing internal fixation, and postoperative infection. Fixation failure, nonunions, malunions, avascular necrosis, and broken hardware were the conditions identified that required reoperation.

An a priori power analysis revealed that to detect a $15 \%$ difference in 5-year mortality with significance at the 5\% level and a power of $80 \%$, a sample of 336 patients would be needed. Our final sample size of 363 patients met these criteria. Data were gathered and stored in Excel 2010 (Microsoft ${ }^{\circledR}$, Redmond, WA, USA). Statistical analysis was performed with SPSS (IBM, New York, NY, USA). Descriptive analyses were performed to compare the demographics (age, sex, ASA) of the members of the study population with members of the control population. We used independent t-tests to compare means of continuous variables, and we used chi-square tests to compare proportions. Mortality after hip fracture was assessed by calculating the median survival times with 95\% CIs, and Cox regression analysis was used for comparison between patients and control subjects. Kaplan-Meier survival analysis with $95 \%$ CI was used to analyze survival after operative management. A probability less than 0.05 was considered statistically significant.

Our analysis included 423 patients with femoral neck fractures between March 24, 1994, and October 11, 2012 (Table 1). One hundred forty-one of these patients had a diagnosis of Parkinson's disease, whereas 282 were without the neurodegenerative disorder. The two groups were similar regarding age, sex, ASA, and fracture type. A majority of the patients were classified as ASA Grade III in both groups. One hundred patients $(71 \%)$ in the Parkinson's group and $200(71 \%)$ in the control group had displaced fractures that were treated with hemiarthroplasty. Of the 100 patients in the Parkinson's disease group who were treated with hemiarthroplasty, $63 \mathrm{had}$ an anterolateral approach and 27 had a posterior approach. Of the 200 patients in the control group who were treated with hemiarthroplasty, 193 had an anterolateral approach and seven had a posterior approach. Forty-one patients in the Parkinson's disease group and 82 in the control group had nondisplaced femoral neck fractures. Thirty-five of the 41 patients in the Parkinson's disease group and 70 of the 82 in the control group were treated with cannulated screw fixation, whereas the other six patients in the Parkinson's group and 12 in the control group were treated with a dynamic hip screw.

A total of 141 patients with Parkinson's disease and femoral neck fractures met criteria for analysis (Fig. 1). An attempt was made to contact all patients with less than 1year followup to determine if they had a postoperative complication, reoperation, or other adverse event. Median followup was 1 year (range, 0-36 months).

\section{Results}

Median survival time of the patients with Parkinson's disease was 31 months (95\% CI, 25-37 months), compared with 45 months (95\% CI, 39-50 months) for the control group. One-year survival was $78 \%$ in both groups. However, the 5-year survival in patients with Parkinson's disease was $10 \%$ (95\% CI, 20\%-40\%) compared with 30\% (95\% CI, 4\%-16\%) in the control group (Fig. 2). Parkinson's disease was shown to be an independent predictor of mortality in our age-, sex-, and operation-matched control group. Predictors of mortality in all patients included presence of Parkinson's disease, male sex, length of stay greater than 7 days, and age older than 80 years (Table 2).

The overall rate of reoperation for patients with Parkinson's disease was greater than for patients without the disease (odds ratio, 3.71; 95\% CI, 1.50-9.177; $\mathrm{p}=0.007$ ). Internal fixation (compared with hemiarthroplasty) was a risk factor for revision surgery $(\mathrm{p}=0.004)$ (Table 3). Three-year freedom from revision was $95 \%$ (95\% CI, 92\%-98\%) in our control group versus $85 \%$ $(95 \% \mathrm{CI}, 79 \%-91 \% ; \mathrm{p}=0.014)$ in the Parkinson's disease group (Fig. 3).

Failure of fixation for patients treated with internal fixation of nondisplaced femoral neck fractures, as defined by the need for a revision operation, was significantly higher in the Parkinson's disease group compared with our control group ( $22 \%$ versus $5 \% ; \mathrm{p}=0.01)$. In a subgroup analysis of all patients treated with cannulated screws, there was a trend toward a higher rate for failure in patients with Parkinson's disease compared with our control group 
Table 1. Demographics of patients with femoral neck fractures with or without Parkinson's disease

\begin{tabular}{|c|c|c|c|}
\hline Variable & Parkinson's disease ( $\mathrm{n}=141$ patients) & No Parkinson's disease ( $\mathrm{n}=282$ patients) & $\mathrm{p}$ value \\
\hline Age at injury (years) & $80 \pm 7$ & $80 \pm 7$ & 0.755 \\
\hline Sex & & & 1.000 \\
\hline Male & $66(47 \%)$ & $132(47 \%)$ & \\
\hline Female & $75(53 \%)$ & $150(53 \%)$ & \\
\hline ASA Classification & & & 1.000 \\
\hline 2 & $29(21 \%)$ & $58(21 \%)$ & \\
\hline 3 & $102(72 \%)$ & $204(72 \%)$ & \\
\hline 4 & $10(7 \%)$ & $20(7 \%)$ & \\
\hline Institution & & & $0.018^{*}$ \\
\hline Massachusetts General Hospital & $91(65 \%)$ & $148(53 \%)$ & \\
\hline Brigham and Women's Hospital & $50(35 \%)$ & $134(47 \%)$ & \\
\hline Time to operating room (days) & $1(1-3)$ & $2(1-3)$ & $0.022 *$ \\
\hline \multicolumn{4}{|l|}{ Fracture } \\
\hline Displaced & $100(71 \%)$ & $200(71 \%)$ & 1.000 \\
\hline Nondisplaced & $41(29 \%)$ & $82(29 \%)$ & 1.000 \\
\hline Length of stay (days) & $6(5-10)$ & $6(5-9)$ & 0.218 \\
\hline
\end{tabular}

* Statistically higher among patients with Parkinson's disease; ASA = American Society of Anethesiologists Physical Status Classification.

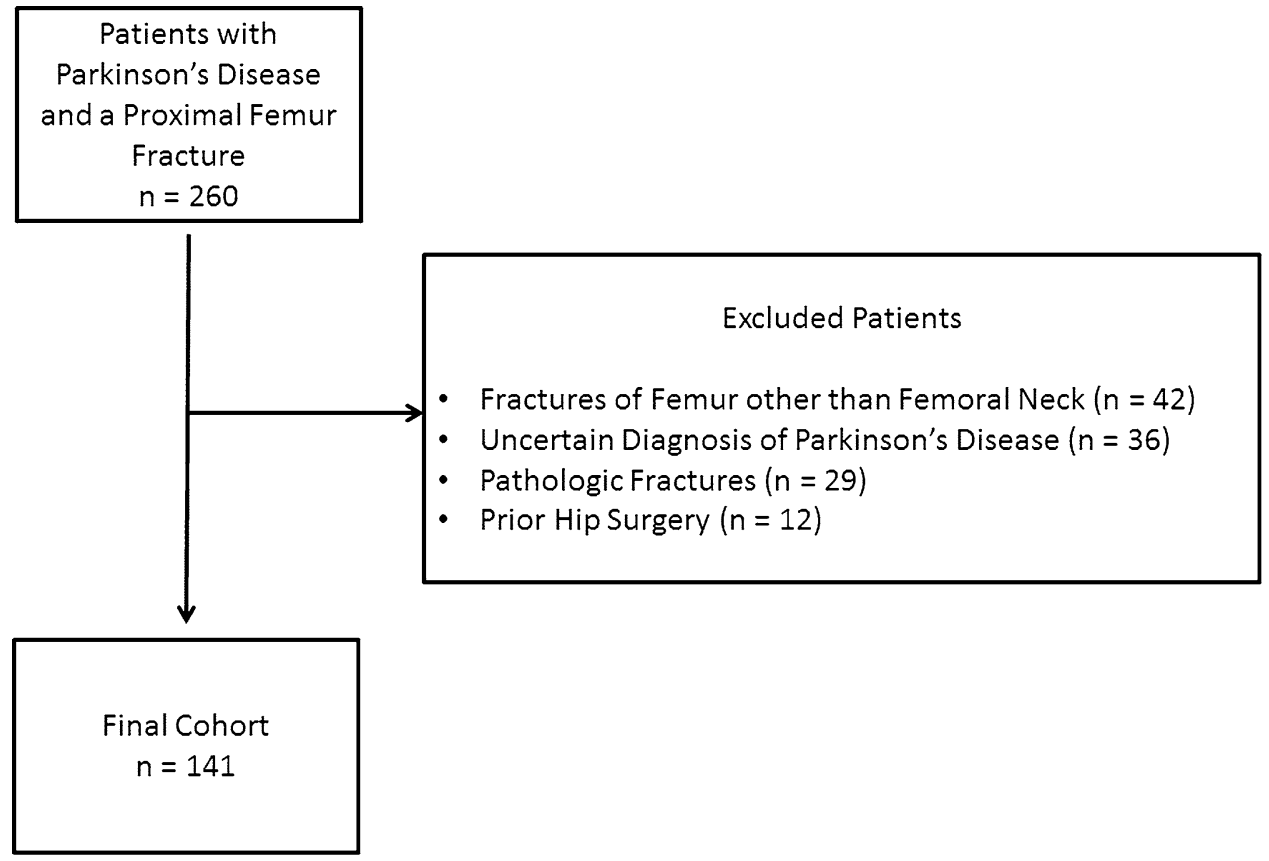

Fig. 1 The flow diagram shows our criteria for patient recruitment. Of 260 patients identified, 141 met the criteria for final analysis.

(6/35 vs. $3 / 70 ; p=0.06)$. Similarly, when we looked at all patients treated with dynamic hip screw fixation, there was a trend toward increased rates of failure in patients with Parkinson's disease compared with the control group, but this did not reach statistical significance (3/6 vs. 1/12; $\mathrm{p}=0.08)$. There was no significant difference comparing the failure rate of patients with Parkinson's disease treated with cannulated screws and a dynamic hip screw (3/6 vs. $6 / 35 ; \mathrm{p}=0.11$ ).

The dislocation rate after hemiarthroplasty for displaced femoral neck fractures was significantly higher in the Parkinson's disease group compared with the control group ( $8 \%$ versus $1 \% ; \mathrm{p}=0.003)$. When the data from both groups were combined, there were more dislocations in 


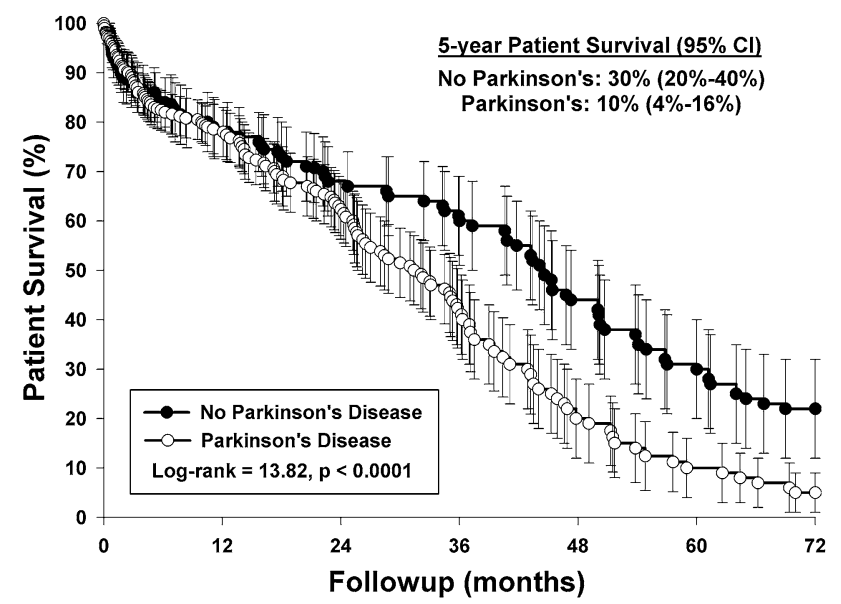

Fig. 2 The Kaplan-Meier survival curve shows 5-year patient survival with $95 \%$ CIs. Five-year survival was $10 \%$ in the control group compared with $30 \%$ in the Parkinson's disease group $(\mathrm{p}<0.0001)$.

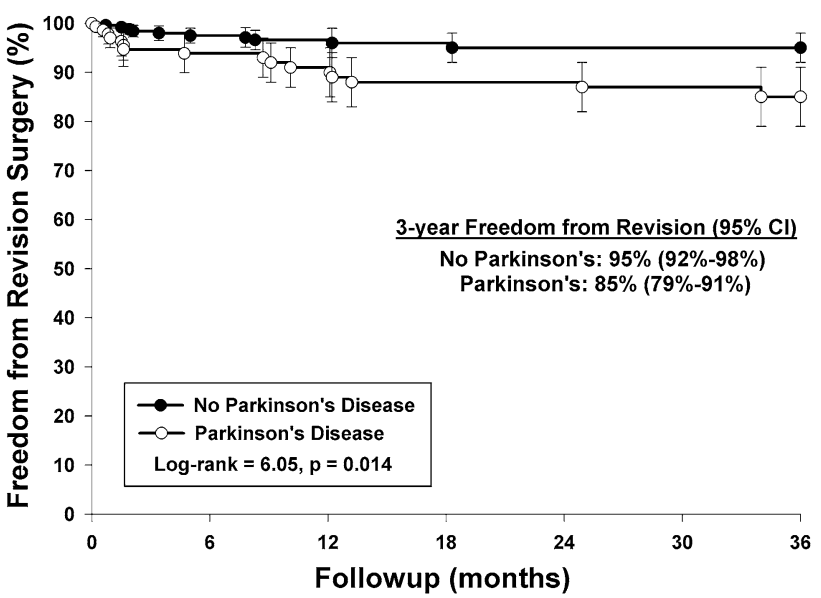

Fig. 3 The Kaplan-Meier survival curve shows freedom from revision at 3 years with 95\% CIs. Three-year freedom from revision was $95 \%$ in the control group compared with $85 \%$ in the Parkinson's disease group $(\mathrm{p}=0.014)$.

Table 2. Significant predictors of mortality based on multivariate logistic regression

\begin{tabular}{llllr}
\hline Covariate & Odds ratio & $95 \%$ CI & Likelihood ratio test $^{\dagger}$ & $\mathrm{p} \mathrm{value}^{\dagger}$ \\
\hline Age older than 80 years & 1.55 & $1.03-2.32$ & 4.47 & $0.035^{*}$ \\
Sex, male versus female & 1.77 & $1.18-2.68$ & 7.70 & $0.006^{*}$ \\
ASA classification & $\mathrm{NA}$ & $\mathrm{NA}$ & 1.68 & 0.431 \\
Institution & $\mathrm{NA}$ & $\mathrm{NA}$ & 0.33 & 0.567 \\
Infection & $\mathrm{NA}$ & $\mathrm{NA}$ & 0.01 & 0.952 \\
Length of stay more than 7 days & 2.04 & $1.31-3.17$ & 10.21 & $0.001^{*}$ \\
Fixation versus hemiarthroplasty & $\mathrm{NA}$ & $\mathrm{NA}$ & 1.35 & 0.245 \\
Parkinson's disease & 1.84 & $1.20-2.84$ & 7.68 & $0.006^{*}$ \\
\hline
\end{tabular}

* Statistically significant independent predictor; ${ }^{\dagger}$ stepwise backward selection; ASA = American Society of Anesthesiologists; NA = not applicable.

Table 3. Significant predictors of revision surgery based on multivariate logistic regression

\begin{tabular}{llllr}
\hline Covariate & Odds ratio & $95 \%$ CI & Likelihood ratio test ${ }^{\dagger}$ & p value \\
\hline Age older than 80 years & NA & NA & 2.35 & 0.126 \\
Sex, male versus female & NA & NA & 1.99 & 0.157 \\
ASA classification & NA & NA & 1.81 & 0.179 \\
Institution & NA & NA & 0.02 & 0.883 \\
Length of stay more than 7 days & 2.04 & $1.31-3.17$ & 0.69 & 0.407 \\
Fixation versus hemiarthroplasty & 4.24 & $1.62-11.0$ & 8.72 & $0.004^{*}$ \\
Parkinson's disease & 3.71 & $1.50-9.77$ & 7.36 & $0.007^{*}$ \\
\hline
\end{tabular}

* Statistically significant independent predictor; ${ }^{\dagger}$ stepwise backward selection; ASA = American Society of Anesthesiologists; NA = not applicable.

patients treated with posterior approaches compared with anterolateral approaches $(14.7 \%$ versus $1.9 \% ; \mathrm{p}=0.002)$. Of the 100 patients with Parkinson's disease who underwent hemiarthroplasty, 63 had an anterolateral approach, and of these, four (6\%) had a dislocation. The remaining 27 patients with Parkinson's disease treated with a hemiarthroplasty had a posterior approach, and of these, four $(15 \%)$ had a dislocation. 


\section{Discussion}

As Parkinson's disease progresses, postural instability increases [7] leading to an increased incidence of falls and associated hip fractures [2]. Although the disease affects $1 \%$ of people older than 65 years [17], data are limited and conflicting whether Parkinson's disease is a distinct prognostic factor when treating femoral neck fractures regarding mortality, rate of reoperation, rate of dislocation, and failure rate of internal fixation. We found that Parkinson's disease is an independent predictor of mortality after operative treatment of femoral neck fractures. In addition, patients with Parkinson's disease are at an increased risk for reoperation, dislocation in the case of hemiarthroplasty, and fixation failure with nondisplaced or minimally displaced fractures.

We recognize the limitations of this study. First, we were unable to classify the severity of Parkinson's disease in our patients. The Unified Parkinson's Disease Rating Scale (UPDRS) is the most commonly used scale in the clinical study of Parkinson's disease [22]. Because the UPDRS is associated with increased mortality [10], classification of our Parkinson's disease group would have allowed us to stratify patients according to the severity of their disease. Second, we were unable to accurately quantify the number of patients with Parkinson's disease who had coexisting dementia. Dementia has been found to occur in $26 \%$ to $89 \%$ of patients with Parkinson's disease [24], and has a direct effect on mortality [36]. Third, although we have complete mortality data through use of the Social Security Death Index, some of our patients had limited followup regarding reoperation, dislocation, failure of fixation, and infection (median, 12 months). Although late mechanical complications after either fracture fixation or hemiarthroplasty occur, most mechanical failures tend to occur within the first few months after surgery [20,34]. We attempted to contact patients, however, given the geriatric population of this study, locating many patients was difficult. The primary outcome of this study is mortality which was queried form the Social Security Death Index and did not rely on clinical records. Finally, we did not isolate specific comorbid medical conditions in our Parkinson's disease group or our control group during the matching process. Instead, we used the ASA classification to provide an approximation of preoperative medical status. Other studies have shown a correlation between ASA and postoperative mortality after hip fracture surgery [3, 8, 16, 31]. However, the ASA does not provide a fine level of detail in terms of comorbid medical conditions [27, 38]. Although we agree this is a limitation, the purpose of using the ASA was only to ensure an approximate equivalency in terms of preoperative medical status, not to identify specific risk factors for mortality.
Mortality after hip fractures has been well documented with 1-year mortality rates varying between $12 \%$ and $37 \%$ $[13,19,23,37]$. Predictors of mortality after hip fracture include male sex, advanced age, high ASA classification, postoperative complications, and major medical comorbidities including cancer, chronic obstructive pulmonary disorder, and congestive heart failure [1, 18]. Early studies suggested that Parkinson's disease may be an independent risk factor for mortality after a hip fracture [6, 35]. Coughlin and Templeton [6] reported a $47 \%$ mortality rate at 6 months in their series of 47 patients. It was postulated that the high mortality rate seen in that series [6] was the result of a lack of emphasis on early postoperative mobility [9]. Since that time, the generally accepted postoperative protocol, pathway, or paradigm has shifted toward early mobilization after hip fracture surgery [30].

More recent studies with larger patient numbers have shown conflicting results regarding mortality differences in patients with Parkinson's disease [11, 21, 25]. Roche et al. [25] reviewed 2448 patients with hip fractures, 97 of whom had Parkinson's disease, and found that Parkinson's disease was not an independent risk factor for 1-year mortality. Similarly, Penrod et al. [21] reviewed 2692 patients with hip fractures, 150 of whom had Parkinson's disease, and found Parkinson's disease was not an independent predictor of 6-month mortality. Most recently, Harris-Hayes et al. [11] reviewed the US Medicare database and were able to analyze 1,980,401 patients with hip and pelvic fractures, 131,215 of whom had Parkinson's disease. They found that the adjusted mortality rate after hip or pelvic fractures in individuals with Parkinson's disease was substantially elevated compared with individuals without the disease.

Our results suggest that Parkinson's disease is an independent predictor of long-term mortality after operative treatment of hip fractures. Although the 1-year mortality rate was similar between patients with Parkinson's disease and without (22\% in both groups), a statistically significant increase in mortality became apparent beyond 2 years. While our study does not address the cause of this increased risk of mortality, it appears that patients with a hip fracture and Parkinson's disease fare poorly. Willis et al. [36] retrospectively reviewed 138,000 patients with Parkinson's disease to determine predictors of survival and found a 6-year mortality of 64\%. Diem-Zangerl et al. [7] reviewed 238 patients with Parkinson's disease and found similar survival between patients with and without Parkinson's disease up to 10 years, with a significant increase in mortality beyond 10 years. In comparison, we present a 5-year mortality rate of $90 \%$ in patients with Parkinson's disease and a hip fracture and only $70 \%$ in patients with a hip fracture alone $(\mathrm{p}<0.0001)$. This suggests that patients with Parkinson's disease and hip fractures are at additional risk for mortality in the longer 
term that cannot be entirely explained by progression of the Parkinson's disease. This increased risk of mortality in patients with hip fractures and Parkinson's disease may be attributable to more severe or advanced Parkinson's disease or the presence of other comorbid conditions that predispose them to a hip fracture in the first place. Regardless of the cause, it appears that patients with a hip fracture and Parkinson's disease fare poorly in the mid- to long-term compared with patients with a hip fracture without Parkinson's disease.

Few studies have analyzed the revision rate after operative treatment of hip fractures in patients with Parkinson's disease, and no clear consensus has been reached for optimal surgical management of this unique patient population. In 1976, Mattson and Louis [15] reported a case of intrapelvic migration of a threaded pin in a patient with Parkinson's disease. They attributed this failure to the rigidity associated with the disease and recommend prosthetic replacement in the case of fracture. In 1980, Coughlin and Templeton [6] reported higher rates of mortality after endoprosthetic replacement compared with internal fixation, leading them to favor internal fixation despite the possibilities of nonunion and avascular necrosis. Later, Londos et al. [14] reviewed 32 displaced and nondisplaced femoral neck fractures in patients with Parkinson's disease treated with internal fixation. Of the 24 displaced femoral neck fractures, six had nonunion and three had avascular necrosis and segmental collapse. Three of the patients required a reoperation. Finally, Turcotte et al. [35] found improved results with internal fixation compared with hemiarthroplasty in patients with Parkinson's disease, stating that hemiarthroplasty "may even be contraindicated." No clear consensus was reached for optimal treatment in cases of displaced and nondisplaced femoral neck fractures, and revision rates after management have not been well established.

Our study showed a statistically significant higher rate of reoperation for patients with Parkinson's disease and nondisplaced femoral neck fractures who were treated with internal fixation $(22 \%$ versus $5 \%$; $=0.01)$. The rate of reoperation in patients with Parkinson's disease with displaced femoral neck fractures was $4 \%$ compared with $22 \%$ in patients with Parkinson's disease with nondisplaced or minimally displaced fractures. Although these groups had different injuries, this finding suggests that consideration should be given to hemiarthroplasty even in patients with Parkinson's disease with minimally displaced femoral neck fractures.

Given the rigidity and cognitive decline associated with Parkinson's disease, dislocation, even with hemiarthroplasty, remains a concern [33]. Coughlin and Templeton [6] reported a dislocation rate of $37 \%$ in patients with Parkinson's disease and hemiarthroplasty for displaced femoral neck fractures. Other studies have shown dislocation rates ranging from $2 \%$ to $14 \%[5,9,32,35]$. Our dislocation rate of $8 \%$ in patients with Parkinson's disease is consistent with these results. We further analyzed the dislocations by operative approach. In our patients with Parkinson's disease, we identified a dislocation rate of $15 \%$ when a posterior approach was used compared with $6 \%$ when an anterolateral approach was used. This suggests that an anterolateral approach should be strongly considered when treating this unique patient population with a hemiarthroplasty.

Our results show that the presence of Parkinson's disease is an independent risk factor for long-term mortality and reoperation after treatment for femoral neck fracture. Patients with Parkinson's disease treated with hemiarthroplasty have a higher dislocation rate compared with patients without the disease. A posterior approach appears to potentiate this risk of dislocation in all patients treated with hemiarthroplasty. Additionally, internal fixation of nondisplaced femoral neck fractures was associated with a significantly higher reoperation rate in patients with Parkinson's disease. Given our results, we believe an anterolateral approach for hemiarthroplasty should be strongly considered. Furthermore, even with nondisplaced or minimally displaced fractures in patients with Parkinson's disease, consideration should be given to hemiarthroplasty to provide a more durable result with a lower risk of reoperation. It is now standard of practice at our institutions to treat all patients with Parkinson's disease and nondisplaced femoral neck fractures with a hemiarthroplasty through an anterolateral approach.

Acknowledgments We thank Jordan Morgan BS (Partners Healthcare, Boston, MA, USA; and Harvard Orthopaedics, Boston, MA, USA) and Susanne Morrison MPH (Partners Healthcare, Boston, MA, USA; and Harvard Orthopaedics, Boston, MA, USA) for their contributions to the data collection process.

\section{References}

1. Aharonoff GB, Koval KJ, Skovron ML, Zuckerman JD. Hip fractures in the elderly: predictors of one year mortality. J Orthop Trauma. 1997;11:162-165.

2. Bhattacharya RK, Dubinsky RM, Lai SM, Dubinsky H. Is there an increased risk of hip fracture in Parkinson's disease? A nationwide inpatient sample. Mov Disord. 2012;27:1440-1443.

3. Bjorgul K, Novicoff WM, Saleh KJ. American Society of Anesthesiologist Physical Status score may be used as a comorbidity index in hip fracture surgery. J Arthroplasty. 2010;25(6 suppl):134-137.

4. Bloem BR, Grimbergen YA, Cramer M, Willemsen M, Zwinderman AH. Prospective assessment of falls in Parkinson's disease. J Neurol. 2001;248:950-958.

5. Boonstra TA, van der Kooij H, Munneke M, Bloem BR. Gait disorders and balance disturbances in Parkinson's disease: clinical update and pathophysiology. Curr Opin Neurol. 2008;21:461-471. 
6. Coughlin L, Templeton J. Hip fractures in patients with Parkinson's disease. Clin Orthop Relat Res. 1980;148:192-195.

7. Diem-Zangerl A, Seppi K, Wenning GK, Trinka E, Ransmayr G, Oberaigner W, Poewe W. Mortality in Parkinson's disease: a 20year follow-up study. Mov Disord. 2009;24:819-825.

8. Donegan DJ, Gay AN, Baldwin K, Morales EE, Esterhai JL Jr, Mehta S. Use of medical comorbidities to predict complications after hip fracture surgery in the elderly. J Bone Joint Surg Am. 2010;92:807-813.

9. Eventov I, Moreno M, Geller E, Tardiman R, Salama R. Hip fractures in patients with Parkinson's syndrome. J Trauma. 1983;23:98-101.

10. Forsaa EB, Larsen JP, Wentzel-Larsen T, Alves G. What predicts mortality in Parkinson disease?: a prospective population-based long-term study. Neurology. 2010;75:1270-1276.

11. Harris-Hayes M, Willis AW, Klein SE, Czuppon S, Crowner B, Racette BA. Relative mortality in US Medicare beneficiaries with Parkinson disease and hip and pelvic fractures. J Bone Joint Surg Am. 2014;96:e27.

12. Lang AE, Lozano AM. Parkinson's disease: first of two parts. N Engl J Med. 1998;339:1044-1053.

13. LeBlanc ES, Hillier TA, Pedula KL, Rizzo JH, Cawthon PM, Fink HA, Cauley JA, Bauer DC, Black DM, Cummings SR, Browner WS. Hip fracture and increased short-term but not longterm mortality in healthy older women. Arch Intern Med. 2011;171:1831-1837.

14. Londos E, Nilsson LT, Stromqvist B. Internal fixation of femoral neck fractures in Parkinson's disease: 32 patients followed for 2 years. Acta Orthop Scand. 1989;60:682-685.

15. Mattson JT, Louis DS. Intrapelvic migration of a threaded Steinmann pin in Parkinson's disease. Clin Orthop Relat Res. 1976;121:166-168.

16. Norring-Agerskov D, Laulund AS, Lauritzen JB, Duus BR, van der Mark S, Mosfeldt M, Jørgensen HL. Metaanalysis of risk factors for mortality in patients with hip fracture. Dan Med J. 2013;60:A4675.

17. Nussbaum RL, Ellis CE. Alzheimer's disease and Parkinson's disease. N Engl J Med. 2003;348:1356-1364.

18. Paksima N, Koval KJ, Aharanoff G, Walsh M, Kubiak EN, Zuckerman JD, Egol KA. Predictors of mortality after hip fracture: a 10-year prospective study. Bull NYU Hosp Jt Dis. 2008;66:111-117.

19. Panula J, Pihlajamaki H, Mattila VM, Jaatinen P, Vahlberg T, Aarnio P, Kivela SL. Mortality and cause of death in hip fracture patients aged 65 or older: a population-based study. BMC Musculoskelet Disord. 2011;12:105.

20. Parker MJ, Pryor G, Gurusamy K. Hemiarthroplasty versus internal fixation for displaced intracapsular hip fractures: a longterm follow-up of a randomised trial. Injury. 2010;41:370-373.

21. Penrod JD, Litke A, Hawkes WG, Magaziner J, Doucette JT, Koval KJ, Silberzweig SB, Egol KA, Siu AL. The association of race, gender, and comorbidity with mortality and function after hip fracture. J Gerontol A Biol Sci Med Sci. 2008;63:867-872.

22. Ramaker C, Marinus J, Stiggelbout AM, Van Hilten BJ. Systematic evaluation of rating scales for impairment and disability in Parkinson's disease. Mov Disord. 2002;17:867-876.

23. Richmond J, Aharonoff GB, Zuckerman JD, Koval KJ. Mortality risk after hip fracture. J Orthop Trauma. 2003;17:53-56.
24. Riedel O, Klotsche J, Spottke A, Deuschl G, Förstl H, Henn F, Heuser I, Oertel W, Reichmann H, Riederer P, Trenkwalder C, Dodel R, Wittchen HU. Cognitive impairment in 873 patients with idiopathic Parkinson's disease: results from the German Study on Epidemiology of Parkinson's Disease with Dementia (GEPAD). J Neurol. 2008;255:255-264.

25. Roche JJ, Wenn RT, Sahota O, Moran CG. Effect of comorbidities and postoperative complications on mortality after hip fracture in elderly people: prospective observational cohort study. BMJ. 2005;331:1374.

26. Rothermel JE, Garcia A. Treatment of hip fractures in patients with Parkinson's syndrome on levodopa therapy. J Bone Joint Surg Am. 1972;54:1251-1254.

27. Sankar A, Johnson SR, Beattie WS, Tait G, Wijeysundera DN. Reliability of the American Society of Anesthesiologists physical status scale in clinical practice. Br J Anaesth. 2014;113:424-432.

28. Sato Y, Honda Y, Iwamoto J. Risedronate and ergocalciferol prevent hip fracture in elderly men with Parkinson disease. Neurology. 2007;68:911-915.

29. Sato Y, Kikuyama M, Oizumi K. High prevalence of vitamin D deficiency and reduced bone mass in Parkinson's disease. Neurology. 1997;49:1273-1278.

30. Siu AL, Penrod JD, Boockvar KS, Koval K, Strauss E, Morrison RS. Early ambulation after hip fracture: effects on function and mortality. Arch Intern Med. 2006;166:766-771.

31. Söderqvist A, Ekström W, Ponzer S, Pettersson H, Cederholm T, Dalén N, Hedström M, Tidermark J; Stockholm Hip Fracture Group. Prediction of mortality in elderly patients with hip fractures: a two-year prospective study of 1,944 patients. Gerontology. 2009;55:496-504.

32. Staeheli JW, Frassica FJ, Sim FH. Prosthetic replacement of the femoral head for fracture of the femoral neck in patients who have Parkinson disease. J Bone Joint Surg Am. 1988;70:565-568.

33. Suh KT, Kim DW, Lee HS, Seong YJ, Lee JS. Is the dislocation rate higher after bipolar hemiarthroplasty in patients with neuromuscular diseases? Clin Orthop Relat Res. 2012;470:1158-1164.

34. Tsang ST, Aitken SA, Golay SK, Silverwood RK, Biant LC. When does hip fracture surgery fail? Injury. 2014;45:10591065.

35. Turcotte R, Godin C, Duchesne R, Jodoin A. Hip fractures and Parkinson's disease: a clinical review of 94 fractures treated surgically. Clin Orthop Relat Res. 1990;256:132-136.

36. Willis AW, Schootman M, Kung N, Evanoff BA, Perlmutter JS, Racette BA. Predictors of survival in patients with Parkinson disease. Arch Neurol. 2012;69:601-607.

37. Wolinsky FD, Fitzgerald JF, Stump TE. The effect of hip fracture on mortality, hospitalization, and functional status: a prospective study. Am J Public Health. 1997;87:398-403.

38. Wolters U, Mannheim S, Wassmer G, Brunkwall J. What is the value of available risk-scores in predicting postoperative complications after aorto-iliac surgery? A prospective non randomized study. J Cardiovasc Surg (Torino). 2006;47:177185.

39. Wood BH, Bilclough JA, Bowron A, Walker RW. Incidence and prediction of falls in Parkinson's disease: a prospective multidisciplinary study. J Neurol Neurosurg Psychiatry. 2002;72:721725 . 